\title{
Composición Fisicoquímica y Propiedades Antioxidantes de Genotipos Nativos de Papa Criolla (Solanum tuberosum Grupo Phureja)
}

\author{
María Cerón-Lasso(1)*, Andrés F. Alzate-Arbeláez ${ }^{(2)}$, Benjamín A. Rojano ${ }^{(2)}$, Carlos E. Nuztez-Lopez ${ }^{(3)}$ \\ (1) Corporación Colombiana de Investigación Agropecuaria- Red de Raíces y Tubérculos, Centro de \\ Investigación Tibaitatá, Km 14 vía Mosquera, Cundinamarca, Colombia (e-mail: mceron@corpoica.org.co) \\ (2) Escuela de Química, Facultad de Ciencias, Universidad Nacional de Colombia, Cl 59ª \# 63-20, Medellín, \\ Antioquia, Colombia. \\ (3) Facultad de Ciencias Agrarias, Universidad Nacional de Colombia, Cra 30 № 45-03 Edifico 500, Bogotá, \\ Colombia. Colombia.
}

${ }^{*}$ Autor a quien debe ser dirigida la correspondencia.

Recibido Ago. 23, 2017; Aceptado Nov. 3, 2017; Versión final Dic. 4, 2017, Publicado Jun. 2018

\section{Resumen}

Se han estudiado las propiedades antioxidantes y composición fisicoquímica de 21 genotipos de papas criollas Solanum tuberosum (Phureja). Se determinó el contenido de humedad, cenizas, proteínas, almidón, azúcares totales y reductores, actividad antioxidante (ABTS y FRAP), fenoles totales y vitamina $\mathrm{C}$. El análisis fisicoquímico mostró variaciones genotípicas significativas en muestra cruda. La humedad entre $72,06 \%$ 77,07\%; cenizas 0,96\% - 2,56\%; proteínas 6,95\% - 11,38\% BS; almidón 14,44\% - 22,4\%; azúcares totales $\mathrm{BH} 16,38 \%-23,67 \%$ y azúcares reductores $\mathrm{BH}$ 0,88\%-3,8\%. El perfil antioxidante evidenció diferencias genotípicas. ABTS entre 4408 - 12543 (crudo) y 6644 a 14492 (cocidas) $\mu \mathrm{mol}$ de Trolox/100g BS. FRAP de 76,4 a 203,2 (crudo) y de 121,6 a 324,8 (cocidas) mg ácido ascórbico/100 g BS. Los fenoles en muestras cocidas fueron mayores que en crudo (245,2 -524,8 y 161,6 - 442,7 mg de ácido gálico/100 g BS, respectivamente, la vitamina C disminuyó entre 33,07\% a 68,8\% luego de cocción.

\section{Physicochemical Composition and Antioxidant Properties of Native Diploid Potato (Solanum tuberosum Phureja Group)}

\begin{abstract}
The antioxidant properties and physicochemical composition of 21 genotypes of diploid potato (Solanum tuberosum Phureja Group) were studied. The content of moisture, ash, proteins, starch, total and reducing sugars, antioxidant activity (ABTS and FRAP), total phenols and vitamin C were determined. The physicochemical analysis showed significant genotypic variations in raw sample. Humidity between $72.06 \%$ 77.07\%; Ash 0.96\% - 2.56\%; Proteins 6.95\% - 11.38\% DB; Starch 14.44\% - 22.4\%; Total sugars WB 16,38\% $-23,67 \%$ and reducing sugars WB $0,88 \%-3,8 \%$. The antioxidant profile showed genotypic differences. ABTS between 4408 - 12543 (raw) and 6644 to 14492 (cooked) $\mu$ mol Trolox / 100g DB. FRAP from 76.4 to 203.2 (raw) and from 121.6 to 324.8 (cooked) ascorbic acid / $100 \mathrm{~g} \mathrm{DB}$. The phenols in cooked samples were higher than in crude (245.2 -524.8 and 161.6 - $442.7 \mathrm{mg}$ gallic acid/100 g BS, respectively, vitamin C decreased from $33.07 \%$ to $68.8 \%$ after cooking.
\end{abstract}

Keywords: antioxidant capacity; diploid potato; physicochemical analysis; nutraceuticals; Solanum tuberosum 


\section{INTRODUCCION}

La papa en Colombia es un producto de alto consumo (61,4 kg per cápita/año), es el principal sistema de producción de clima frío. La superficie de cultivo en 2014 fue de 142.108 ha con producción estimada de 2.157.568 t, de las cuales la papa criolla (Solanum tuberosum Grupo Phureja) aportó 9.954,9 ha con producción de 132.323,5 t. Las principales zonas productoras de papa criolla son: Cundinamarca $(3081,25$ ha), Boyacá (1905,0 ha), Nariño (1601,0 ha) y Antioquia (1540,0 ha) (AGRONET, 2016). Las propiedades nutricionales de las papas han sido ampliamente estudiadas y reportadas, se resalta su aporte de carbohidratos, proteínas y fibra dietaría como componentes mayoritarios; vitaminas del complejo B como tiamina (B1), niacina (B3) y B6, así como vitamina C, y los minerales: magnesio, hierro, calcio, potasio y fósforo (Zaheer and Akhtar, 2016)

La papa es importante fuente de nutrientes en la dieta humana, aporta sustancias bioactivas que presentan actividad antioxidante; destacándose como un alimento completo. Los compuestos presentes en los tubérculos de papa con potencial antioxidante son: ácido ascórbico, a-tocoferol, carotenoides, diferentes polifenoles y ácidos fenólicos como el ácido clorogénico, principal representante de este grupo. Tanto la carne como la cáscara de la papa contienen sustancias antioxidantes, se ha demostrado que la mayoría de los compuestos fenólicos se encuentran en la cáscara, derivados mayoritariamente del ácido caféico y ácido ferúlico, estimulando así el aprovechamiento de este subproducto en la industria alimentaria (Akyol et al., 2016). Los antioxidantes cumplen funciones protectoras frente a desordenes propios del equilibrio redox del organismo, disminuyendo los efectos adversos que causan radicales libres, principalmente las especies reactivas de oxígeno que se derivan de la respiración celular. La determinación de la capacidad antioxidante in vitro de un alimento proporciona una medida de su poder redox o comportamiento antirradical dentro de los tejidos y células corporales tras situaciones de estrés oxidativo (Bianchi y Falcioni, 2016).

Diversas accesiones de Solanum tuberosum han mostrado valores de capacidad antioxidante comparativamente más altos que otros cultivos de igual importancia como arroz, trigo y maíz. Varios genotipos de papa (Solanum tuberosum subsp. andigena) presentan colores rojizos y purpuras tanto en cáscara como en carne, estos colores se deben a la presencia de antocianinas en el tubérculo (Burgos et al., 2013). Colombia posee amplia diversidad genética en papa del Grupo Phureja, elevado consumo nacional y alta tradición de cultivo en la comunidad campesina y buen consumo nacional, el objetivo de esta investigación fue evaluar el potencial antioxidante y la composición fisicoquímica de 21 genotipos de papa criolla Solanum tuberosum Grupo Phureja sembrados en el Municipio de El Rosal (Cundinamarca-Colombia).

\section{MATERIALES Y METODOS}

El experimento se realizó en El Municipio de El Rosal (Cundinamarca, Colombia) a 4ำ52'32.62'N; 74ํ1' $17.61^{\prime \prime} \mathrm{O}$ y $2689 \mathrm{msnm}$, con temperatura promedio de $15,6^{\circ} \mathrm{C}$, precipitación media de $825,94 \mathrm{~mm}$, humedad relativa de $86,54 \%$, suelos de textura limosa, $\mathrm{pH} 5,24$ y fertilización media. Se sembró en abril de 2014 y se cosechó en agosto del mismo año. Se evaluaron 21 genotipos de papa criolla (Solanum tuberosum Grupo Phureja), procedentes del Banco de Germoplasma Vegetal que administra CORPOICA, relación que se presenta en la figura 1. Se sembraron bajo el diseño de bloques completos al azar con 3 repeticiones, unidad experimental de 3 surcos por $5 \mathrm{~m}$ de longitud $\left(15 \mathrm{~m}^{2}\right)$. De cada unidad experimental se cosechó el surco central, separando tres plantas, de las que se tomó una muestra al azar de diez tubérculos para las respectivas evaluaciones fisicoquímicas, capacidad antioxidante, fenoles totales y vitamina C, realizando en triplicado por cada repetición de campo. Las prácticas agronómicas fueron las convencionales para el cultivo de papa criolla. Se realizó control manual de malezas, aplicación de fungicidas para manejo de la gota (Phytophthora infestans (Mont) de Bary) y el manejo de insectos plaga según necesidades. La fertilización se realizó con el compuesto 13-26-6 en dosis de 22 g/planta en la siembra.

Los tubérculos fueron cosechados con madurez fisiológica entre 110 a 119 días. Para muestras frescas y cocidas, se tomaron en forma independiente tres tubérculos de tres plantas del surco central de cada unidad experimental; fueron lavados con agua corriente y destilada. Los tubérculos para procesar en fresco se cortaron de forma longitudinal (peso de muestra $50 \mathrm{~g}$ ), se congelaron con nitrógeno líquido y se llevaron a conservación a $-70,8^{\circ} \mathrm{C}$. Posteriormente, se liofilizaron, molieron, pasaron por tamiz No. 40 y fueron almacenados hasta los análisis. Para tubérculos cocidos las muestras se cocieron a $90{ }^{\circ} \mathrm{C}$ por 9 min. Se dejaron enfriar a temperatura ambiente y se conservaron a $-70,8^{\circ} \mathrm{C}$ hasta su liofilización, luego estas muestras liofilizadas se almacenaron hasta los análisis a $-70,8^{\circ} \mathrm{C}$. Para la composición fisicoquímica, se realizaron los porcentajes de humedad, materia seca, proteínas, azúcares reductores, azúcares totales, almidón y cenizas. 


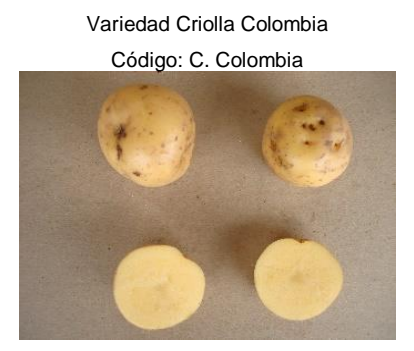

Genotipo: 15061980 Código:G1980

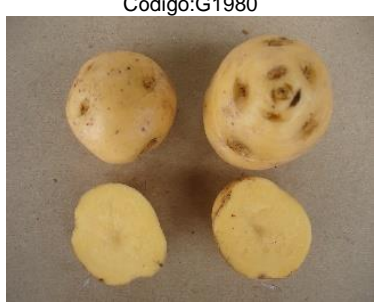

Genotipo: 15062027 Código: G2027

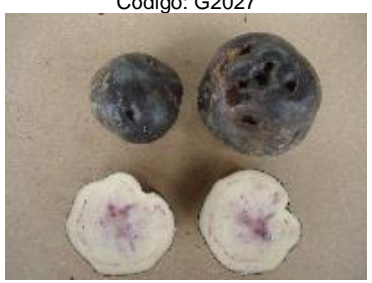

Genotipo: 15062588

Código:G2588

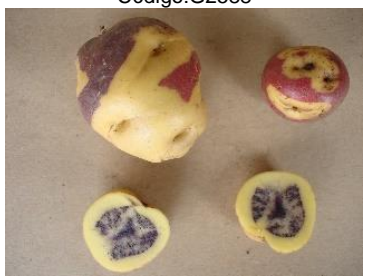

Genotipo: 15062593

Código:G2593

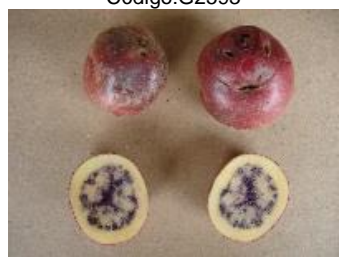

Genotipo: 15061989

Código: G1989

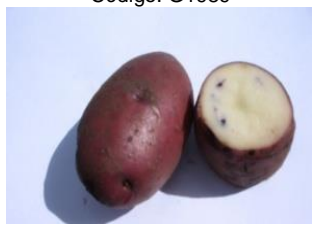

Genotipo: 15060077

Código: G0077

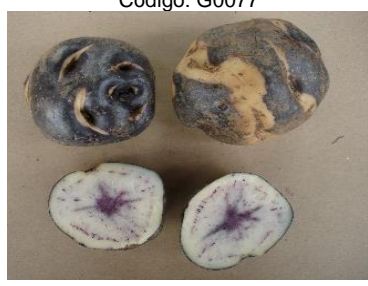

Genotipo: 15061997 Código:G1997

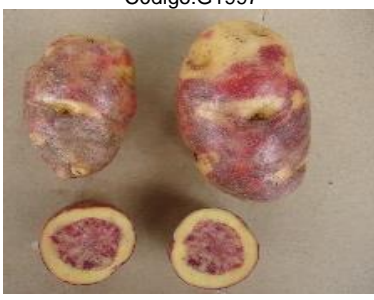

Genotipo: 15062515

Código: G2515

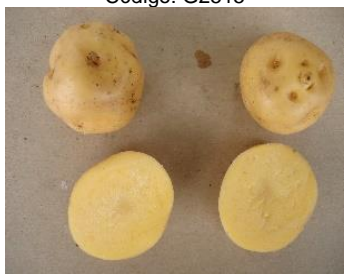

Genotipo: 15062589

Código:G2589

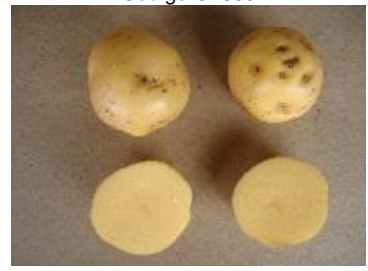

Genotipo: 15062594

Código:G2594

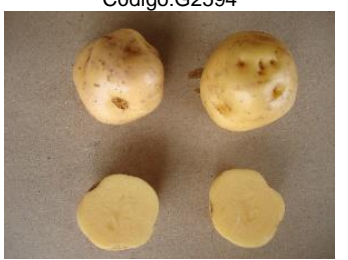

Genotipo: 15060204

Código: G0204

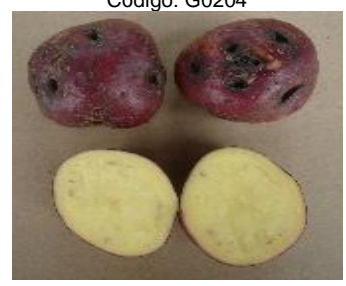

Genotipo: 15062020 Código: G2020

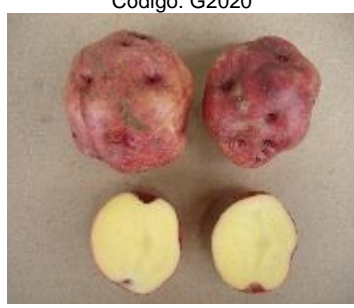

Genotipo: 15062585 Código: G2585

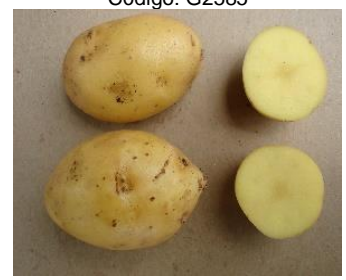

Genotipo: 15062590

Código: G2590

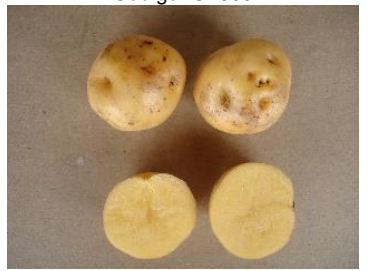

Genotipo: 15062596

Código: G2596

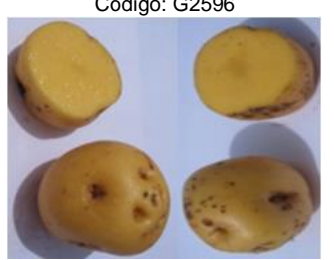

Genotipo: 15061781

Código: G1781

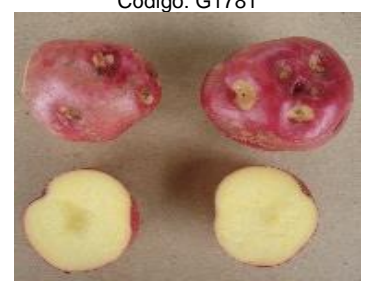

Genotipo: 15062021 Código: G202

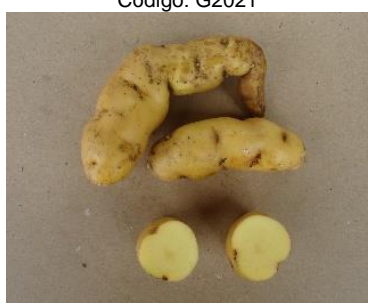

Genotipo: 15062586 Código: G2586

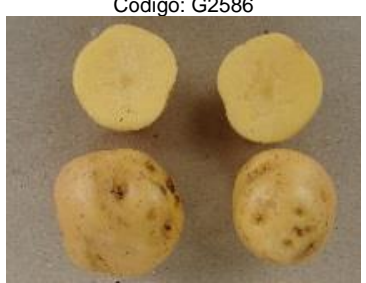

Genotipo: 15062591

Código: G2591

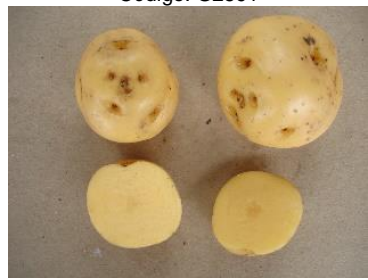

Genotipo: 15062599

Código: G2599

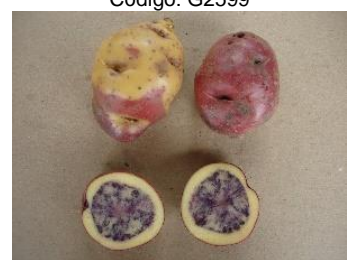

Fig. 1: Genotipos nativos de papa criolla (Solanum tuberosum Grupo Phureja), cultivados en Colombia

\section{Humedad y Materia Seca}

El contenido de materia seca se cuantificó por medio del método AOAC 925.10 (AOAC, 2005). La humedad se calculó por diferencia de peso.

\section{Proteínas en base humedad y base seca}

Cuantificadas por el método colorimétrico de Biuret de la AOAC 935.11 (AOAC, 2005) que se basa en la reacción de las proteínas y péptidos con iones de cobre en solución alcalina, formando un quelato color violeta. Se utilizó como patrón de referencia albúmina sérica bovina. Las mediciones se realizaron en un equipo Spectronic $20^{\circledR}$ a una longitud de onda de $540 \mathrm{~nm}$. 


\section{Azúcares reductores}

Los tubérculos crudos fueron licuados, una porción de 0,5-1g fue disuelta hasta completar un volumen de 100 $\mathrm{mL}$ con agua destilada, luego fue homogenizada y centrifugada a $2500 \mathrm{rpm}$ por $10 \mathrm{~min}$. A $1 \mathrm{~mL}$ de sobrenadante con $0,5 \mathrm{~mL}$ con DNS (ácido 3,5 dinitrosalicilico) reaccionaron en baño maría durante $5 \mathrm{~min}$. Se enfrió en baño de hielo y se tomaron lecturas en el espectrofotómetro Spectronic20 ${ }^{\circledR}$ a una longitud de onda de $540 \mathrm{~nm}$ (Miller, 1959). La curva patrón empleada se realizó en concentraciones de 0,$11 ; 0,17 ; 0,23 ; 0,36$; 0,41 y $0,5 \mathrm{mg} / \mathrm{mL}$

\section{Azúcares totales}

Para su determinación se adicionó a la muestra del tubérculo crudo ácido clorhídrico por 1 min con el fin de realizar un rompimiento de las cadenas de los azúcares no reductores en monosacáridos y se determinaron con el método de Miller (1959).

\section{Almidón}

Hace parte de los azúcares no reductores, se determinaron por diferencia entre los azucares totales y reductores (Zárate-Polanco et al., 2014).

\section{Cenizas}

Para cuantificar las cenizas se empleó el método de la AOAC 940.26 (AOAC, 2005), se pesaron 4-5 g de papa que fueron llevados a un crisol de porcelana previamente pesado, se calcinó en estufa a $500^{\circ} \mathrm{C}$ durante $2 \mathrm{~h}$ hasta obtener cenizas de color blanco.

\section{Método del radical catiónico ABTS}

La capacidad para atrapar radicales libres, se realizó empleando el método del radical catiónico ABTS [2,2'Azino-bis (3-etilbenzotiazolina-6-ácido sulfónico) sal diamonio]. Se mezclaron en tubos de ensayo $10 \mu \mathrm{L}$ de muestra y $990 \mu \mathrm{L}$ de solución de ABTS, por separado se preparó una referencia y un blanco, en el caso de la referencia se utilizaron $10 \mu \mathrm{L}$ del solvente de la muestra más $990 \mu \mathrm{L}$ de ABTS, $734 \mathrm{~nm}$, y 30 min de reacción a temperatura ambiente. El cálculo de la actividad antioxidante se realizó empleando una curva de calibración y usando Trolox como antioxidante de referencia, los resultados fueron reportados como TEAC: Trolox Equivalent Antioxidant Capacity ( $\mu \mathrm{mol}$ de Trolox/100 g de muestra liofilizada-BS) (Re et al., 1999).

\section{FRAP (Ferric Reducing Antioxidant Power)}

El poder reductor en muestras de papa se evaluó mediante la metodología de Benzie y Strain (1996), con modificaciones menores. La mezcla de reacción estaba formada por: $\mathrm{FeCl}_{3}$, tripiridil triazina y buffer de acetatos a pH 3,4. Las cantidades para el ensayo fueron las siguientes: $900 \mu \mathrm{L}$ de la solución anterior, $50 \mu \mathrm{L}$ de muestra y $50 \mu \mathrm{L}$ de solución de buffer acetato $\mathrm{pH} 3,4$. Transcurridos $30 \mathrm{~min}$ de reacción se determinó la absorbancia a una longitud de onda de $593 \mathrm{~nm}$. La curva de calibración se construyó usando ácido ascórbico como estándar. El poder reductor de las papas se expresó como AEAC (ascorbic acid equivalent antioxidant capacity: $\mathrm{mg}$ de ácido ascórbico/100 g de muestra liofilizada-BS)

\section{Fenoles Totales}

Se determinó siguiendo el procedimiento descrito por Zapata et al., 2013. En tubos de ensayo se adicionaron los siguientes reactantes: $50 \mu \mathrm{L}$ de muestra, $125 \mu \mathrm{L}$ de reactivo de Folin-Ciocalteau, $400 \mu \mathrm{L}$ de carbonato de sodio al 7,1\% y $425 \mu \mathrm{L}$ de agua tipo I. Se preparó un blanco sustituyendo el reactivo de Folin por agua tipo I. La mezcla reaccionó durante $1 \mathrm{~h}$, finalizado este período se registró la absorbancia a $760 \mathrm{~nm}$. Los fenoles totales se expresaron como mg equivalentes de ácido gálico (AG), la unidad de medida es mg Eq AG/100 g de muestra liofilizada (BS).

\section{Ácido Ascórbico}

Se cuantificó como vitamina $C$ en los tubérculos mediante cromatografía liquida, según lo descrito por Shakya y Navarre (2006) con algunas modificaciones. Se utilizó un cromatógrafo Shimadzu ${ }^{\circledR}$ de la línea Prominence ${ }^{\circledR}$. La fase móvil fue una solución de ácido fórmico al 0,1\% en agua purificada, mediante sistema de elución isocrático y flujo de $0,8 \mathrm{ml} / \mathrm{min}$. La fase estacionaria fue una columna LiChrospher ${ }^{\circledR} 100 \mathrm{RP}-18(5 \mu \mathrm{m}) \mathrm{Merck}^{\circledR}$ de dimensiones: largo $250 \mathrm{~mm}$ y diámetro interno de $4 \mathrm{~mm}$ mantenida a una temperatura de $35^{\circ} \mathrm{C}$ durante todo el análisis. Se inyectaron $20 \mu \mathrm{L}$ de muestra, el contenido de vitamina $\mathrm{C}$ fue calculado mediante una curva de calibración usando estándar de ácido ascórbico (AA) grado HPLC (Sigma-Aldrich). El tiempo de retención mostrado por el estándar fue de 3,9 min y su detección por medio de PDA a $245 \mathrm{~nm}$. La vitamina C se expresó como mg Eq AA/100 g de muestra liofilizada (BS). 


\section{Análisis estadístico}

Para establecer el efecto de los genotipos evaluados sobre las variables consideradas, se realizaron los análisis de varianza (ANOVA), previo cumplimiento de los supuestos de normalidad y homocedasticidad de los residuales. Estos análisis fueron complementados con pruebas de comparación múltiple de Tukey $(\alpha=0,05)$. Los procedimientos estadísticos fueron realizados utilizando programa SAS versión 9.3.

\section{RESULTADOS Y DISCUSION}

Los resultados del análisis fisicoquímico en muestras crudas mostraron diferencias para los genotipos evaluados en las variables en estudio, excepto en proteínas (Tabla 1). El rango en materia seca (MS) osciló entre $22,76 \% \pm 0,77$ y $27,94 \% \pm 1,12$; los genotipos G2589, G2585 y G1997, obtuvieron los mayores porcentajes de MS, fueron superiores a los genotipos G0204, G2599 y G1781 e iguales a los restantes genotipos (tabla 2). Un elevado contenido de materia seca es deseable para la obtención de productos derivados como papas fritas con elevada calidad, evitando la presencia de colores y sabores desagradables y economizando aceite en el proceso de freído (Loyola et al., 2010). El contenido de MS de los genotipos evaluados en el presente trabajo concuerda con lo reportado por Dale et al. (2003) quienes estudiaron 33 genotipos de S. tuberosum cultivados en tres sitios geográficamente diversos en Europa: Inglaterra, Italia y Alemania.

Tabla 1: Cuadrados medios del análisis de varianza para las variables fisicoquímicas en tubérculos de los genotipos evaluados (S. tuberosum Grupo Phureja) ${ }^{1}$ expresado en porcentaje $\quad{ }^{*}=$ Diferencias significativas. $\quad{ }^{* *}=$ Diferencias altamente significativas.

\begin{tabular}{|c|c|c|c|c|c|c|c|c|}
\hline F.V. & G.L. & $\begin{array}{l}\text { Materia } \\
\text { Seca }^{1}\end{array}$ & $\begin{array}{c}\text { Proteína } \\
B H^{1}\end{array}$ & Almidón ${ }^{1}$ & Humedad $^{1}$ & Cenizas $^{1}$ & $\begin{array}{l}\text { Azucares } \\
\text { Totales }^{1}\end{array}$ & $\begin{array}{c}\text { Azucares } \\
\text { Reductores }^{1}\end{array}$ \\
\hline Bloque & 2 & 1,713 & 0,071 & 0,078 & 1,713 & 0,094 & 0,355 & 0,112 \\
\hline Genotipos & 20 & $6,453^{* *}$ & 0,233 & $10,71^{* *}$ & $6,453^{\star *}$ & $0,502^{\star *}$ & $8,371^{* *}$ & $1,835^{\star *}$ \\
\hline Error & 40 & 1,578 & 0,138 & 2,168 & 1,578 & 0,120 & 2,009 & 0,098 \\
\hline C.V. & & 4,99 & 16,64 & 7,99 & 1,68 & 25,12 & 6,94 & 15,79 \\
\hline
\end{tabular}

Tanto en azúcares no reductores como en almidón, se encontraron diferencias significativas; en la segunda variable destacan los genotipos G2589, C. Colombia, G2591 y G2020, que poseen valores mayores a 20\%, lo que los convierte en potenciales para la obtención de almidones nativos como materia prima de diversos productos alimenticios. Lo opuesto ocurrió con los genotipos: G0204, G1781, G0077 y G2021, con 14,4\% a $16,9 \%$ (Tabla 2); estudios reportados por Ngobese et al. (2017), confirman la variación en el contenido de almidones al estudiar ocho cultivares de Solanum tuberosum sembrados en Sudáfrica; las variedades Navigator e Innovator obtuvieron el valor más alto en su orden 18,1 y $17,9 \%$, que los demás cultivares (13,7 y $15,4 \%)$.

Las proteínas en base húmeda $(\mathrm{BH})$ mostraron un rango entre $1,73 \% \pm 0,19$ y $2,81 \% \pm 1,18$ y de $6,95 \%$ a $11,38 \%$ en base seca (BS), sin diferencias entre genotipos (Tabla 2). Rodríguez et al. (2011), reportaron en genotipos del Grupo Phureja cultivados en Colombia, la heredabilidad del contenido de proteína total en 103 familias F1 de hermanos medios maternos, bajo diferentes métodos estadísticos, entre $28 \%$ y $41 \%$, con un incremento de proteína entre 0,55 a 0,79; el alto consumo del tubérculo de papa de la población alto andina, incidirá favorablemente en la ingesta de proteínas en la dieta, aunque la papa no es una fuente abundante en proteínas si aporta la mayoría de aminoácidos esenciales como: isoleucina, leucina, lisina, metionina, fenilalanina, treonina, y valina, (Ježek et al., 2011).

El genotipo G2599 con 2,56\% de cenizas en BH, presentó el mayor valor, siendo similar a los valores observados en cinco genotipos adicionales: G2588, G2591, G2594, G2586 y G1781 con porcentajes entre $1,77 \%$ y $2,05 \%$ y superior al genotipo testigo Criolla Colombia con 1,32\%. El rango de la variable osciló entre 0,96\% y 2,56\% (Tabla 2); Peña et al. (2015), reportaron en el Grupo Phureja cultivados en Nariño, Colombia, valores de cenizas desde 0,7 a $1,1 \mathrm{~g} / 100 \mathrm{~g}$. peso fresco, menores a los encontrados en este estudio. La variación de los genotipos en estudio evidencia un amplio rango en el contenido mineral, explicado en parte por condiciones del suelo y características genéticas de fijación de micronutrientes.

Los genotipos evaluados presentaron diferencias en el contenido de azúcares totales. G2589 obtuvo la mayor cuantificación con $23,67 \%$ en BS y el menor valor lo obtuvo G0204 con 16,38\% de BS. El menor porcentaje de azúcares reductores se obtuvo en los genotipos G2591 y G2594 con 0,88\% y 0,98\% de BS en su orden, característica importante para la utilización de los tubérculos en procesos de poscosecha como fritura. Tanto para los azúcares totales como reductores (Tabla 2), concuerdan con la literatura reportada por (Peña et al., 2015). 
Tabla 2. Análisis fisicoquímico en tubérculos de genotipos cosechados en el Municipio de El Rosal, Cundinamarca, Colombia. *Resultados expresados en porcentaje \pm SD. Letras diferentes demuestran diferencias significativas, Tukey ( $p$ $<0,05)$.

\begin{tabular}{|c|c|c|c|c|c|c|c|}
\hline Genotipos & $\begin{array}{c}\text { Materia Seca } \\
\text { (MS) (\%) }\end{array}$ & Almidón (\%) & $\begin{array}{c}\text { Proteínas } \\
\text { BH (\%) }\end{array}$ & $\begin{array}{c}\text { Proteínas } \\
\text { BS (\%) }\end{array}$ & $\begin{array}{c}\text { Cenizas BH } \\
(\%)\end{array}$ & $\begin{array}{c}\text { Azucares } \\
\text { Totales BS } \\
(\%) \\
\end{array}$ & $\begin{array}{c}\text { Azucares } \\
\text { Reductores } \\
\text { BS (\%) }\end{array}$ \\
\hline G2589 & $27.94 \pm 1.12 a$ & $22.4 \pm 1.0 a$ & $2.05 \pm 0.06 a$ & $7.35 \pm 0.06 a$ & $1.1 \pm 0.14 b c$ & $23.67 \pm 0.95 a$ & $1.27 \pm 0.12 \mathrm{ghi}$ \\
\hline G2585 & $27.55 \pm 0.82 a$ & $17.64 \pm 2.9 b c d$ & $2.15 \pm 0.37 a$ & $7.80 \pm 0.37 a$ & $1.32 \pm 0.2 b c$ & $19.52 \pm 2.3 a-d$ & $1.88 \pm 0.6 d-g$ \\
\hline G1997 & $27.30 \pm 0.94 a$ & $19.85 \pm 0.08 a b$ & $2.33 \pm 0.12 a$ & $8.41 \pm 0.12 a$ & $1.03 \pm 0.0 b c$ & $22.25 \pm 0.21 a b$ & $2.40 \pm 0.29 \mathrm{cde}$ \\
\hline G2591 & $26.64 \pm 1.01 a b$ & $20.30 \pm 1.0 a b$ & $2.04 \pm 0.67 a$ & $7.66 \pm 0.67 a$ & $1.95 \pm 0.46 a b c$ & $21.17 \pm 0.63 a b c$ & $0.88 \pm 0.26 h i$ \\
\hline G2594 & $26.48 \pm 1.38 a b$ & $19.65 \pm 0.35 a b c$ & $2.25 \pm 0.53 a$ & $8.5 \pm 0.53 a$ & $1.57 \pm 0.62 a b c$ & $20.65 \pm 0.54 a-d$ & $0.98 \pm 0.74 h i$ \\
\hline G2515 & $25.89 \pm 0.0 a b$ & $16.69 \pm 0.0 b c d$ & $2.70 \pm 0.0 a$ & $10.44 \pm 0.0 a$ & $1.05 \pm 0.0 b c$ & $18.68 \pm 0.0 b c d$ & $1.99 \pm 0.0 c-g$ \\
\hline G1989 & $25.80 \pm 0.0 a b$ & $19.74 \pm 0.0 a b$ & $2.61 \pm 0.0 a$ & $10.12 \pm 0.0 a$ & $1.34 \pm 0.0 b c$ & $21.69 \pm 0.0 a b c$ & $1.95 \pm 0.0 c-h$ \\
\hline $\begin{array}{l}\text { C. } \\
\text { Colombia }\end{array}$ & $25.67 \pm 2.45 a b$ & $20.40 \pm 0.07 a b$ & $2.25 \pm 0.20 a$ & $8.75 \pm 0.20 a$ & $1.32 \pm 0.22 b c$ & $21.77 \pm 0.57 a b c$ & $1.40 \pm 0.50 f-i$ \\
\hline G1980 & $25.65 \pm 1.16 a b$ & $19.23 \pm 0.95 a b c$ & $2.15 \pm 0.28 a$ & $8.39 \pm 0.28 a$ & $1.27 \pm 0.20 b c$ & $20.61 \pm 1.03 a-d$ & $1.38 \pm 0.14 f-i$ \\
\hline G2596 & $25.20 \pm 1.70 a b$ & $19.64 \pm 3.35 a b c$ & $1.92 \pm 0.45 a$ & $7.62 \pm 0.45 a$ & $1.19 \pm 0.56 b c$ & $21.09 \pm 3.46 a b c$ & $1.44 \pm 0.19 e-i$ \\
\hline G2588 & $25.17 \pm 0.47 a b$ & $17.78 \pm 0.47 \mathrm{bcd}$ & $2.36 \pm 0.51 a$ & $9.38 \pm 0.51 a$ & $2.05 \pm 0.16 a b$ & $19.71 \pm 0.38 a-d$ & $1.93 \pm 0.11 c-h$ \\
\hline G2027 & $24.91 \pm 1.07 a b$ & $17.36 \pm 0.36 b c d$ & $1.73 \pm 0.19 a$ & $6.95 \pm 0.19 a$ & $1.05 \pm 0.0 b c$ & $20.26 \pm 0.06 a-d$ & $2.90 \pm 0.3 a b c$ \\
\hline G2020 & $24.76 \pm 0.42 a b$ & $20.24 \pm 0.96 a b$ & $2.35 \pm 0.33 a$ & $9.48 \pm 0.33 a$ & $1.21 \pm 0.44 b c$ & $22.21 \pm 0.74 a b$ & $1.97 \pm 0.22 c-g$ \\
\hline G2593 & $24.69 \pm 4.09 a b$ & $18.26 \pm 3.63 a-d$ & $2.81 \pm 1.18 a$ & $11.38 \pm 1.18 a$ & $1.07 \pm 0.16 b c$ & $20.77 \pm 3.30 a-d$ & $2.51 \pm 0.33 b c d$ \\
\hline G2586 & $24.42 \pm 0.81 a b$ & $18.53 \pm 0.81 \mathrm{a}-\mathrm{d}$ & $2.04 \pm 0.19 a$ & $8.17 \pm 0.19 a$ & $1.67 \pm 1.01 a b c$ & $19.69 \pm 0.66 a-d$ & $1.15 \pm 0.14 \mathrm{ghi}$ \\
\hline G0077 & $24.34 \pm 1.17 a b$ & $16.77 \pm 0.59 b c d$ & $1.94 \pm 0.11 a$ & $7.97 \pm 0.11 a$ & $1.1 \pm 0.21 b c$ & $19.61 \pm 0.45 a-d$ & $2.83 \pm 0.14 a-d$ \\
\hline G2590 & $24.08 \pm 0.38 a b$ & $18.12 \pm 0.85 a-d$ & $1.91 \pm 0.11 a$ & $7.94 \pm 0.11 a$ & $1.34 \pm 0.44 b c$ & $19.51 \pm 1.09 a-d$ & $1.38 \pm 0.24 f-i$ \\
\hline G2021 & $24.05 \pm 0.11 a b$ & $16.92 \pm 0.26 b c d$ & $2.18 \pm 0.22 a$ & $9.06 \pm 0.22 a$ & $0.96 \pm 0.08 b c$ & $20.31 \pm 0.40 a-d$ & $3.40 \pm 0.14 a b$ \\
\hline G0204 & $22.95 \pm 0.79 b$ & $14.44 \pm 1.40 d$ & $2.58 \pm 0.05 a$ & $11.19 \pm 0.05 a$ & $1.11 \pm 0.11 b c$ & $16.38 \pm 1.59 c d$ & $1.94 \pm 0.19 c-h$ \\
\hline G2599 & $22.93 \pm 0.0 b$ & $18.08 \pm 0.0 a-d$ & $2.41 \pm 0.0 a$ & $7.33 \pm 0.0 a$ & $2.56 \pm 0.0 a$ & $21.88 \pm 0.0 a b$ & $3.80 \pm 0.0 a$ \\
\hline G1781 & $22.75 \pm 0.77 b$ & $15.07 \pm 0.90 \mathrm{~cd}$ & $2.21 \pm 0.21 a$ & $9.69 \pm 0.21 a$ & $1.77 \pm 0.64 a b c$ & $17.39 \pm 1.02 c d$ & $2.33 \pm 0.24 c-f$ \\
\hline
\end{tabular}

\section{Actividad antioxidante}

La actividad antioxidante de genotipos de papa criolla colombiana S. tuberosum grupo Phureja fue evaluada mediante dos metodologías ABTS*+ y FRAP. En la primera se determinan moléculas antioxidantes que ejercen su acción mediante un mecanismo de trasferencia de protones (HAT); en la metodología FRAP se determina el poder reductor mediante transferencia de electrones desde los antioxidantes hasta un átomo de $\mathrm{Fe}^{3+}$, provocando su reducción. Ambas metodologías son complementarias y permiten caracterizar adecuadamente una compleja matriz alimentaria como son las papas, (Liu 2010; Benzie y Szeto, 1999). Las muestras fueron evaluadas crudas y cocidas con el fin de conocer la incidencia del proceso de cocción sobre la calidad nutracéutica.

En la actividad antioxidante (ABTS y FRAP) se presentaron diferencias significativas entre genotipos, de igual manera para el tipo de muestra (crudo y cocido) y la interacción genotipo por tipo de muestra (Tabla 3).

\section{ABTS}

En los genotipos estudiados, se encontró variación en la actividad antioxidante por ABTS, el rango en muestra cruda fue de $4408,3 \pm 300,8$ y $12542,8 \pm 113,2$ con una media de 7665,15 , mientras que en muestra cocida varió entre $6643,8 \pm 246,7$ a 14492,9 $\pm 378,12$ con una media de 9452,05 TEAC- $\mu$ mol de Trolox/100g BS, la tasa de retención luego del proceso de cocción osciló entre 1,08 a 1,76 veces (Fig. 2), observando un aumento significativo de la actividad antioxidante luego del proceso de cocción. Este resultado concuerda con lo reportado por Navarre et al. (2010), la capacidad antioxidante aumento de 28,7 en muestra cruda a 36,3 $\mu \mathrm{mol}$ Trolox/g peso seco después del cocido en puré de la variedad Purple Majesty, cultivada en Washington Estados Unidos. 
Tabla 3: Cuadrados medios para capacidad antioxidante (ABTS-FRAP), fenoles totales y vitamina $C$ en genotipos evaluados (S. tuberosum Grupo Phureja)

\begin{tabular}{|c|c|c|c|c|c|}
\hline F.V. & G.L. & ABTS & FRAP & $\begin{array}{c}\text { Fenoles } \\
\text { totales }\end{array}$ & Vitamina C \\
\hline Bloque & 2 & 1163,2 & 102,33 & 366,05 & 0,57 \\
\hline Tipo muestra (TM) & 1 & $92151234,00^{\star *}$ & $309441,24^{\star *}$ & $171183,71^{* *}$ & $2044,84^{* *}$ \\
\hline Genotipos (Genot) & 20 & $17892542,60^{\star *}$ & $10174,76^{* *}$ & $28351,86^{\star *}$ & $5,19^{*}$ \\
\hline TM* Genot & 20 & $1130970,70^{* *}$ & $1577,38^{* *}$ & $1453,09^{* *}$ & $5,31^{*}$ \\
\hline Error & 80 & 59874,8 & 116,492 & 216,42 & 2,655 \\
\hline Total & 123 & & & & \\
\hline C.V. & & 2,84 & 6,83 & 4,87 & 14,57 \\
\hline
\end{tabular}

ABTS (TEAC- $\mu$ mol Trolox/100g BS); FRAP (mg ácido ascórbico/100 g BS); Fenoles totales (mg ácido gálico $(\mathrm{GAE}) / 100 \mathrm{~g} \mathrm{BS})$. Vitamina $\mathrm{C}$ (mg de ácido ascórbico/100 g BS). * $=$ Diferencias significativas. ${ }^{* *}=$ Diferencias altamente significativas.

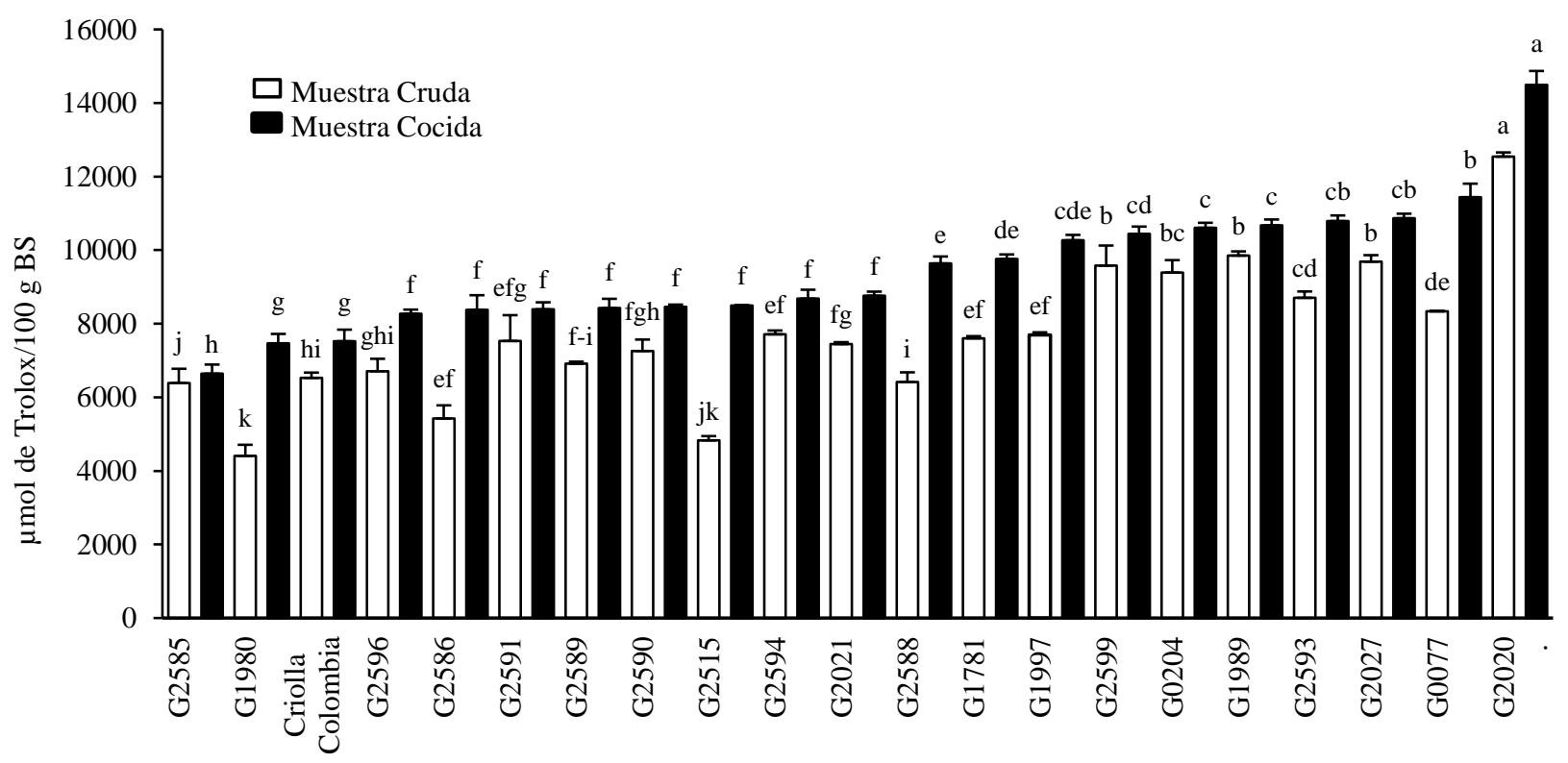

Fig. 2: Valores de ABTS dado en $\mu \mathrm{mol}$ de Trolox/100 g BS, para 20 genotipos de papas nativas y la variedad Criolla Colombia ( $S$. tuberosum Grupo Phureja). Letras diferentes demuestran diferencias significativas, Tukey $(p<0,05)$

Cuatro fueron los genotipos que obtuvieron mayores valores de la actividad antioxidante por ABTS: G2020, G2599, G0204, G2593; destacándose el genotipo G2020 en muestra cruda 12542,8 \pm 407,6 y en muestra cocida 14492,9 $\pm 378,12 \mu \mathrm{mol}$ de Trolox/100g BS. Le siguieron tres genotipos que también superaron a los demás genotipos en estudio (G2599, G1989, G2593) (Fig. 2). Estos resultados fueron similares a lo reportado por Al-Weshahy y Rao (2009). La mayor expresión de ABTS se obtuvo en genotipos de colores rojo y morado oscuro en la cáscara, luego del proceso de cocción; resultados similares fueron descritos por Rosenthal y Jansky (2008) en clones de tubérculos con piel y carne intensamente púrpura o roja, cultivados en Estados unidos.

Los 11 genotipos de color amarillo en su cáscara y pulpa tuvieron menores valores de la actividad antioxidante por ABTS (Fig. 2), resultados afines fueron mostrados por Grudzińska et al. (2016), donde la tasa de retención de crudo a cocida fue de 1,76 veces. En el estudio sobresalieron: G2594 en muestra cruda 7712,7 $\pm 104,1$ y en muestra cocida $8684,1 \pm 240,5$ y G2586 en muestra cruda $7568,9 \pm 357,2$ y en muestra cocida $8377 \pm$ 397,6 $\mu \mathrm{mol}$ de Trolox/100g BS. (Fig. 2). 


\section{FRAP}

La respuesta del poder reductor (FRAP), en los genotipos evaluados en muestras crudas y cocidas mostraron cambios significativos en la actividad antioxidante con un aumento para las muestras cocidas; la tasa de retención luego del proceso de cocción estuvo entre 1,59 a 2,35 veces más. Los resultados concuerdan con los reportados por Bontempo et al. (2013); menores valores de los reportados fueron obtenidos por AlWeshahy y Rao (2009) con valores que están entre 0,43 a 1,07 mg/100g BS.

En el estudio se destacaron los genotipos de cáscara roja por su alto valor de actividad antioxidante medido por FRAP, el rango osciló en muestras crudas entre 76,4 \pm 16 a 203,25 \pm 4,7 y en muestras cocidas entre $121,6 \pm 14$ a 324,81 $\pm 5 \mathrm{mg}$ ácido ascórbico/100 g BS, la tasa de retención luego del proceso de cocción estuvo entre 1,6 a 2,35 veces más. Sobresalió el genotipo G2020 en muestra cruda 203,25 \pm 4,7 y en cocida $324,81 \pm 5,0 \mathrm{mg}$ ácido ascórbico/100 g BS. (Fig. 3), siendo significativamente superior a los demás genotipos estudiados.

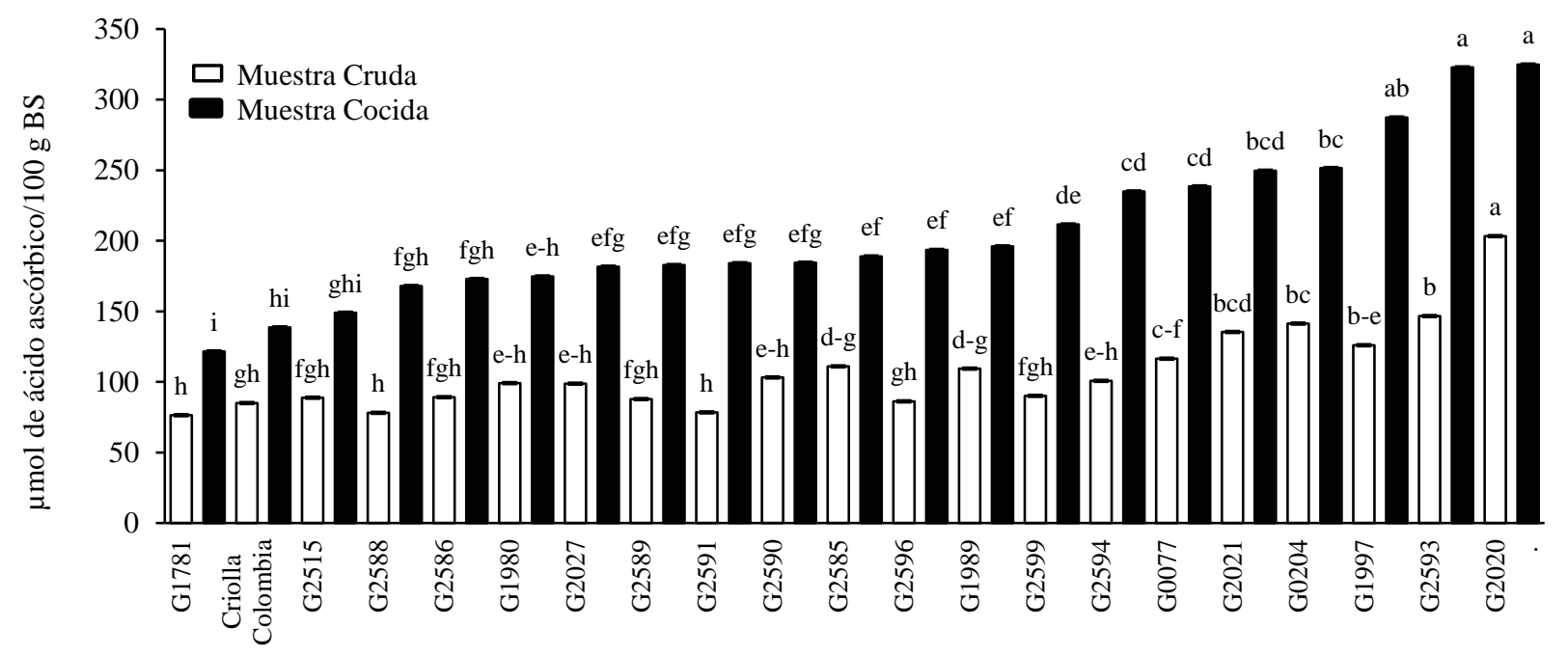

Fig. 3: Valores de FRAP dado en $\mu$ mol de ácido ascórbico/100 g BS, para 20 genotipos de papas nativas y la variedad Criolla Colombia ( $S$. tuberosum Grupo Phureja). Letras diferentes demuestran diferencias significativas, Tukey $(p<0,05)$

La actividad antioxidante medida por FRAP de 5 genotipos de color morado oscuro en su cáscara oscilaron en muestras crudas desde 76,43 $\pm 11,1$ a 125,96 $\pm 11,3$ y en muestras cocidas de $121,62 \pm 7$ a 287,31 \pm 4,4 mg ácido ascórbico/100 g BS., la tasa de recuperación de muestra cruda a cocida estuvo entre 1,59 a 2,28 veces. Se destacaron los genotipos: G1997 en muestra cruda 125,96 $\pm 11,3$ y en muestra cocida $287,31 \pm$ 4,4; G0077 en muestra cruda 116,44 \pm 6,1 y en muestra cocida 238,51 $\pm 14,2$ y G1989 en muestra cruda $109,40 \pm 7,2$ y en muestra cocida $196 \pm 13,7 \mathrm{mg}$ ácido ascórbico/100 g BS (Fig. 3). Menores valores de los reportados fueron obtenidos por Al-Weshahy y Rao (2009) para tubérculos sembrados en Ontario Canadá, con valores que estuvieron entre 0,43 a $1,07 \mathrm{mg} / 100 \mathrm{~g} \mathrm{BS}$, posiblemente debido al tipo de genotipo y el método de extracción.

La actividad antioxidante medida por FRAP de 11 genotipos de cáscara y pulpa amarilla osciló en muestras crudas entre 78,37 $\pm 10,5$ a 135,38 $\pm 11,9$ y en cocidas de 138,6 \pm 18 a 249,59 \pm 7,9 mg ácido ascórbico/100 g BS, la tasa de recuperación de muestras crudas a cocidas fue de 1,63 a 2,35 veces. Resultados diferentes fueron observados en papas cultivadas en Reino Unido (Lemos et al., 2015) por FRAP con $67 \pm 5 \mathrm{mM} / 100$ $\mathrm{BH}$ en muestras crudas y $79 \pm 5 \mathrm{mM} / 100 \mathrm{BH}$ en muestras cocidas de tubérculos color morado. Los resultados demuestran que la actividad antioxidante en papa se correlaciona con el contenido fenólico en los genotipos en estudio. Los genotipos con mejor poder reductor fueron en su orden: G2020, G2593, G1997, G2021, G0204, G0077 (Fig. 3).

La ingesta de papas comparada con otros vegetales es alta, (171.4 g/día en EE.UU), genera un aporte antioxidante considerable, ocupando el tercer lugar después de productos derivados de naranja y manzana, (Chun et al., 2005). 


\section{Metabolitos antioxidantes}

Los tubérculos de S. tuberosum Grupo Phureja son una fuente importante de compuestos con actividad antioxidante como carotenoides, polifenoles y ácido ascórbico (Burgos et al., 2009). Los metabolitos antioxidantes (fenoles totales y Vitamina $\mathrm{C}$ ), presentaron diferencias significativas entre genotipos, de igual manera para el tipo de muestra (crudo y cocido) y la interacción genotipo por tipo de muestra se relacionó en la Tabla 3.

La Figura 4 muestra los genotipos evaluados por el contenido de fenoles totales, cuantificando $263,59 \pm 11,19$ en muestras crudas y $338,18 \pm 14,33$ en muestras cocidas; el rango estuvo entre $161,6 \pm 14,2$ a $442,7 \pm 37,5$ para muestras crudas y en muestras cocidas de $245,2 \pm 7,6$ a $524,8 \pm 8,4 \mathrm{mg}$ ácido gálico/100 $\mathrm{g} \mathrm{BS}$. La tasa de retención luego del proceso de cocción fluctuó entre 1,11 a 1,72 veces. Estos resultados coinciden con lo reportado por Burgos et al. (2013), quienes evaluaron muestras cocidas, cultivadas en Junín, Perú.

En la Figura 4 se observa que los genotipos de color rojo en cáscara obtuvieron los mayores valores para el contenido de fenoles totales, la tasa de recuperación de crudo a cocido fue de 1,18 a 1,51 veces. El genotipo G2020 destacó tanto en muestras crudas $442,73 \pm 37,5$ como en cocidas $524,75 \pm 8,4 \mathrm{mg} \mathrm{GAE} / 100 \mathrm{~g}$ BS y presentó diferencias significativas $(p>0,001)$ respecto a los otros genotipos evaluados incluida Criolla Colombia. Le siguieron los genotipos de color rojo en su cáscara: G0204 en muestras crudas 376,66 $\pm 18,5$ y en cocidas $453,29 \pm 25,7$; G2599 en muestras crudas $348,44 \pm 13,3$ y en cocidas $449,09 \pm 18,1$; G2593 en muestra cruda $324,82 \pm 18,7$ y en cocida $381,76 \pm 10,2 \mathrm{mg} \mathrm{GAE} / 100 \mathrm{~g}$ BS; Karim et al. (2017), reportaron en cinco variedades de papa de Solanum tuberosum, Grupo Chilotanum, el contenido de polifenoles totales en muestras de tubérculos sin cáscara entre 320,59 y 528,94 mg de $100 \mathrm{~g}$ de peso seco (DW) en tubérculos crudos y 282,03-543,96 $\mathrm{mg}$ de $100 \mathrm{~g}$ de DW en tubérculos cocidos.

La tasa de recuperación de fenoles totales en muestras crudas en genotipos de color rojo y morado oscuro con relación a los genotipos de color amarillo estuvo entre 1,65 a 2,74 veces más y en muestras cocidas fue 1,85 a 2,14 veces más; Navarre et al. (2010), reportaron compuestos fenólicos entre 1,8 a $11 \mathrm{mg} / \mathrm{g}$ BS; Burlingame et al. (2009), lograron cantidades hasta de $1570 \mu \mathrm{g} / 100 \mathrm{~g}$ BS posiblemente atribuidos a las modificaciones físicas y químicas del tubérculo durante el proceso de cocción que afecta el valor nutricional y funcional del mismo. Burgos et al. (2013), reportaron mayor cuantificación de fenoles totales en tubérculos cocidos que en crudos de 4 cultivares evaluados, la variedad Guincho obtuvo la mayor cuantificación de 596 a $4196 \mathrm{mg}$ de ácido clorogénico Equivalentes/100 g BS en papas crudas y de 915 a $4525 \mathrm{mg}$ Equivalentes de ácido clorogénico /100 g BS.

Menores valores de fenoles totales se presentaron en genotipos de cáscara y pulpa color amarillo (Fig. 4). La variación en los resultados de muestras crudas y cocidas de los genotipos en estudio, se debe posiblemente al comportamiento diferencial de la tasa de recuperación de estos compuestos, así lo confirman los estudios reportados por Faller y Fialho (2009) con brócoli y papa cultivados en Brasil bajo manejo tradicional demostrando la mayor tasa de recuperación de los polifenoles solubles e hidrolizables en muestras crudas a cocidas, la papa obtuvo la mayor tasa de recuperación. La variación del contenido de fenoles totales en los genotipos estudiados, permitirán seleccionar aquellos de interés por sus características funcionales e involucrarlos en programas de mejoramiento tendientes a obtener cultivares con altos compuesto fenólicos. Se ha reportado que una ingesta adecuada de fenoles produce efectos beneficos de la salud en humanos; especialmente en enfermedades crónicas, incluido el cáncer, las enfermedades cardiovasculares y trastornos neurodegenerativos (Vauzour et al., 2010).

En la Figura 5, se presentan los contenidos de vitamina $C$ en los 21 genotipos evaluados, el rango en muestras crudas osciló desde de 12,85 a 17,56 mg ácido ascórbico/100 g BS, con una media de 15.24; y de 4,69 hasta $10,02 \mathrm{mg}$ ácido ascórbico/100 g BS, con una media de 7,09 mg ácido ascórbico/100 g BS, en tubérculos cocidos (Figura 5). La cocción disminuyó entre un 33,07 hasta un $68,8 \%$ el contenido de vitamina C. Sobresalieron genotipos de cáscara y pulpa amarilla por su valor de vitamina $\mathrm{C}$, el rango osciló para muestras crudas de 12,85 $\pm 3,36$ a 17,39 $\pm 1,98$ y en muestras cocidas de 4,69 $\pm 0,57$ a 10,02 $\pm 0,42 \mathrm{mg}$ ácido ascórbico/100 g BS; el porcentaje de recuperación de cruda a cocida estuvo entre $31,20 \%$ al $66,93 \%$; reportes de Navarre et al. (2010), mostraron que la vitamina C puede decrecer de $20 \%$ al $60 \%$ dependiendo del genotipo; Burgos et al. (2009) mostró que la variedad 704393 obtuvo alta concentración de ácido ascórbico en BS (105,1-121,4 mg/100g) y en FW (33,6-34.0 mg/100 g). En los genotipos en estudio sobresalió G2585 en muestra cruda con 14,97 $\pm 3,32$ y en muestra cocida 10,02 $\pm 0,42 \mathrm{mg}$ ácido ascórbico/100 g BS. Estudios reportados por Burgos et al. (2009) en 6 variedades de papa obtuvieron una tasa de retención de vitamina C del $53 \%$ al $97 \%$ en papas cocidas. 


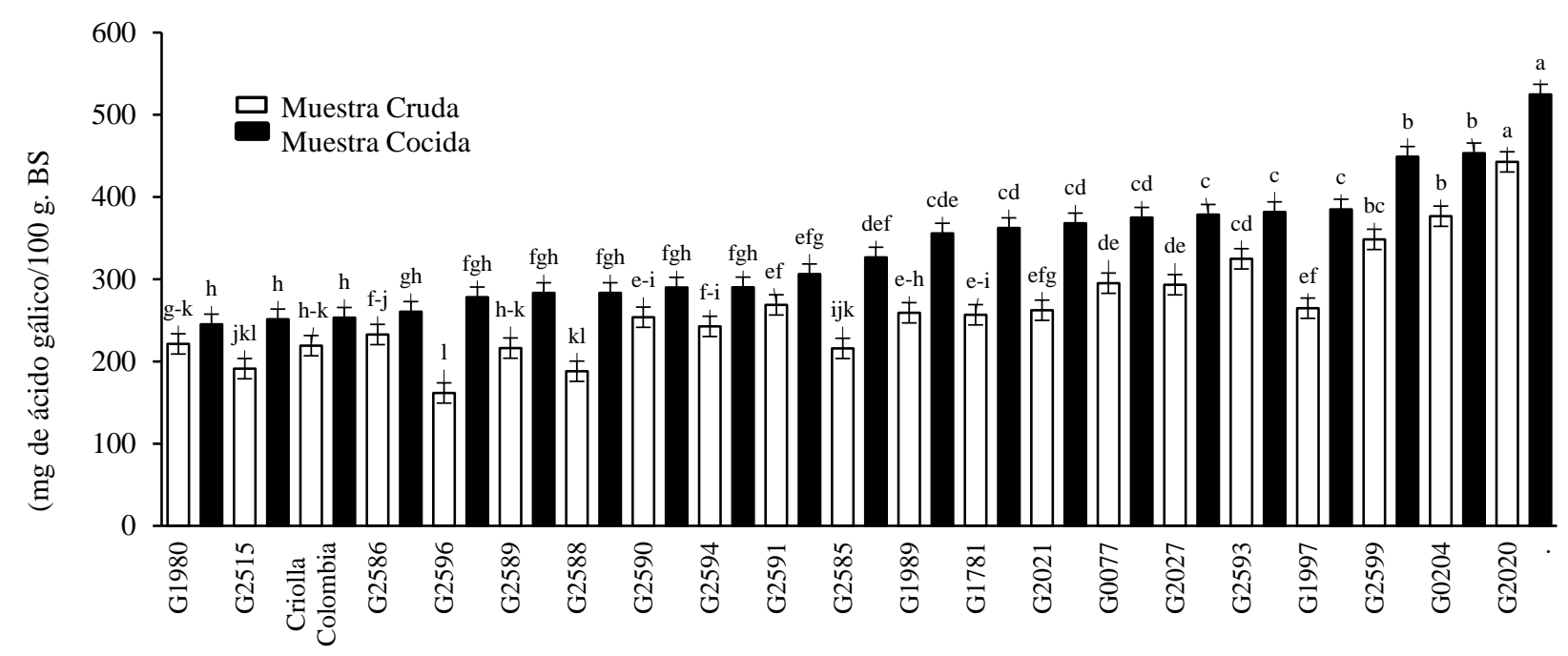

Fig. 4: Valores de fenoles totales dado en $\mathrm{mg}$ de ácido gálico/100 g BS., para 20 genotipos de papas nativas y la variedad Criolla Colombia ( $S$. tuberosum Grupo Phureja). Letras diferentes demuestran diferencias significativas, Tukey $(p<0,05)$

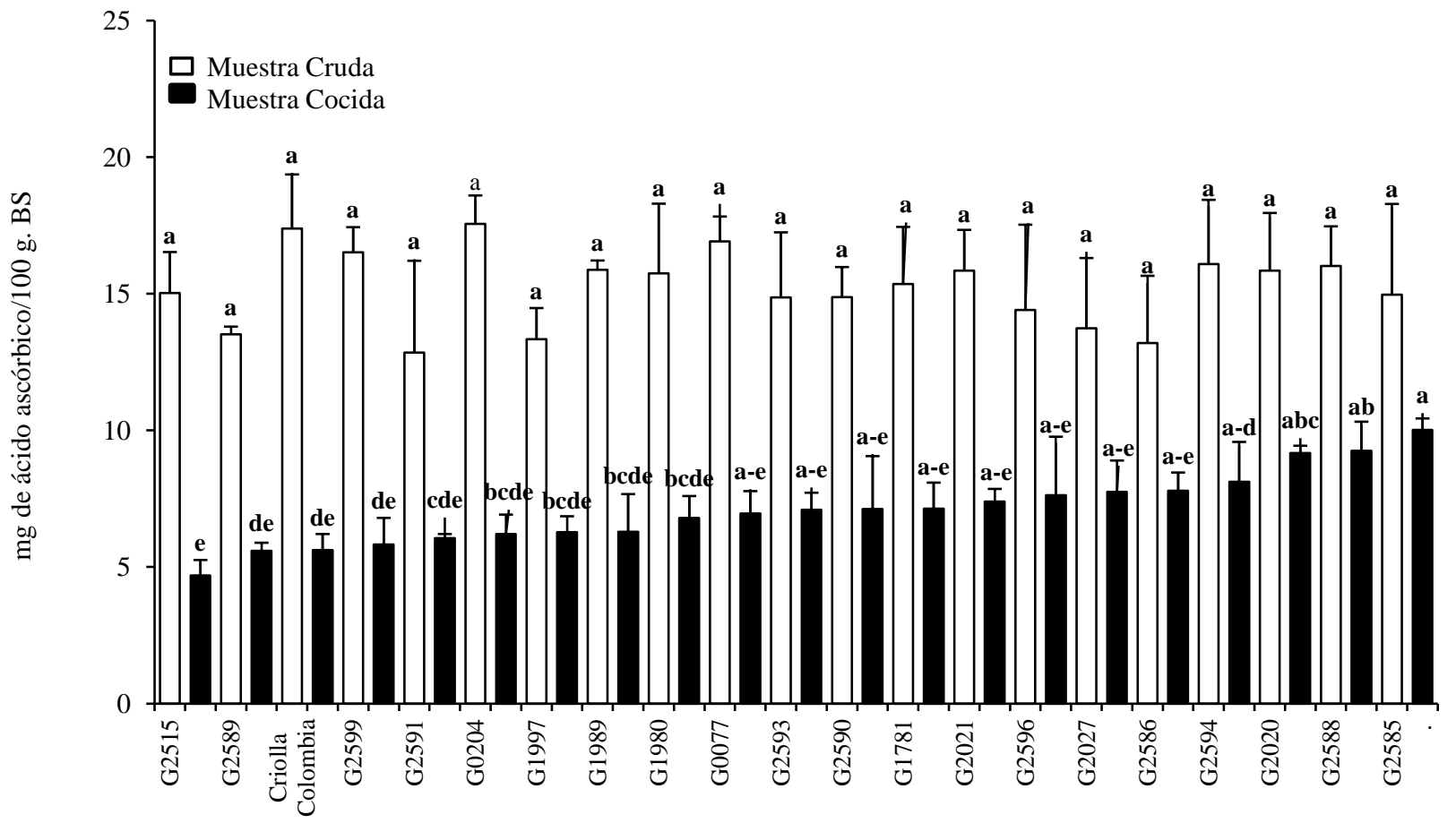

Fig. 5: Contenido de vitamina $\mathrm{C}$ dado por mg de ácido ascórbico/100 g BS., para 20 genotipos de papas nativas y la variedad Criolla Colombia ( $S$. tuberosum Grupo Phureja). Letras diferentes demuestran diferencias significativas, Tukey $(p<0,05)$

En el contenido de Vitamina $C$ para 5 genotipos de color en cascara morado oscuro, se destacó el genotipo G2027 en muestra cruda 13,74 $\pm 2,57$ y en muestra cocida 7,75 \pm 1,15 mg ácido ascórbico/100 g BS; diferentes son los estudios reportados sobre la retención en cocido, uno de ellos de Hejtmánková et al. (2009) obtuvieron en variedades con carne púrpura 1,4 veces menos de ácido ascórbico que aquellas variedades de color amarillo, todas ellas cultivadas en Republica Checa. Reportes diferentes a los del estudio fueron dados por Navarre et al. (2010), en la variedad Purple Magesty bajo diferentes métodos de cocción, las

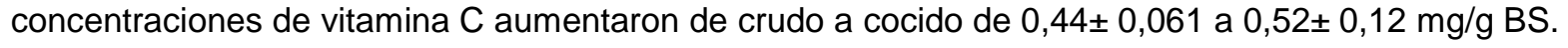


El genotipo G2020 de color rojo en su cáscara obtuvo valores altos en fenoles totales y vitamina C. Reportes realizados por Navarre et al. (2010) sobre la papa de piel roja, proporciona aproximadamente el $36 \%$ de la cantidad recomendada en la dieta. El genotipo G2585 obtuvo el valor más alto en vitamina C para los genotipos de color amarillo en su cascara y carne. Drewnowski y Rehm (2013) reportaron en 98 hortalizas evaluadas que la papa era la fuente menos costosa de vitamina $C$ al calcular el costo para suministrar el $10 \%$ de la dieta recomendada. La Organización Mundial de la Salud recomienda una ingesta diaria de 45 a 90 $\mathrm{mg} / \mathrm{día}$ de vitamina C, un consumo de $100 \mathrm{~g}$ de papas cocidas, aportaría entre el $7 \%-15 \%$ del valor diario recomendado. Burgos et al. (2009) encontraron en papas nativas del Grupo Phureja y Andigena que luego del proceso de cocción por ebullición el contenido de ácido ascórbico disminuyó significativamente.

\section{CONCLUSIONES}

De la presente investigación destaca que los genotipos evaluados no son muy diferentes de los cultivados en otras latitudes tanto en Latinoamérica como en Europa o Asia. También es de subrayar la presencia de contenidos superiores de proteínas, almidón azúcares y minerales que aportan en el balance de una buena dieta. Además de la presencia de compuestos antioxidantes como fenoles y ácido ascórbico.

Teniendo en cuenta que Colombia aun cuenta con zonas muy desfavorecidas económicamente donde el acceso a diferentes alimentos es bajo, la papa cubre muchas de las necesidades nutricionales básicas y energéticas, en este sentido se pretende promover la calidad nutricional de estos genotipos usándolos como parentales donantes en programas de mejoramiento genético de papa criolla o para ingresarlos al sistema productivo de la zona alto andina colombiana. En especial los genotipos G2020, (que destaca en la mayoría de los análisis), seguido de los clones G2021, G0204, G0077 y G2027.

\section{AGRADECIMIENTOS}

Los autores agradecen al Ministerio de Agricultura y Desarrollo Rural de Colombia y a La Corporación Colombiana de Investigación Agropecuaria (Corpoica) por su financiación. De igual forma al Grupo de Especialistas de La Unidad de Estadística de Corpoica por su apoyo en los análisis estadísticos.

\section{REFERENCIAS}

AGRONET. Ministerio de Agricultura y Desarrollo Rural. República de Colombia. Red de Información y comunicación del sector agropecuario Colombiano. Ministerio de Agricultura y Desarrollo Rural de Colombia. Recuperado de http://www.agronet.gov.co/Paginas/default.aspx (2017)

Akyol, H.; Y. Riciputi; E. Capanoglu; M.F. Caboni; y V. Verardo, Phenolic Compounds in the Potato and Its Byproducts: An Overview, doi:10.3390/ijms17060835, International Journal of Molecular Sciences, 17(6), 835 (2016)

Al-Weshahy, A.; y V. Rao, Isolation and characterization of functional components from peel samples of six potatoes varieties growing in Ontario, Food Research International, 42(8), 1062-1066 (2009)

AOAC: Association of Official Analytical Chemists, official methods of analysis, 18a Ed. (2005)

Benzie, I.F.; y J.J. Strain, The Ferric Reducing Ability of Plasma (FRAP) as a Measure of Antioxidant Power: The FRAP assay, Analytical Biochemistry, 239(1), 70-76 (1996)

Benzie, I.F. y Y.T. Szeto, Total Antioxidant Capacity of Teas by the Ferric Reducing/ Antioxidant Power Assay. J. Agric. Food Chem., 47, 633-636 (1999)

Bianchi, V.E.; y G. Falcioni, Reactive oxygen species, health and longevity, doi: 10.3934/molsci.2016.4.479, AIMS Molecular Science, 3(4), 479-504 (2016).

Bontempo, P., V. Carafa; R. Grassi; A. Basile; G. Tenore; C. Formisano; D. Rigano; y L. Altucci, Antioxidant, antimicrobial and anti-proliferative activities of Solanum tuberosum L. var. Vitelotte, Food and Chemical Toxicology, 55, 304-312(2013)

Burgos, G.; W. Amoros; E. Salas; L. Muñoa; P. Sosa; E. Cayhualla; C. Sanchez; C. Díaz; y M. Bonierbale, Total phenolic, total anthocyanin and phenolic acid concentrations and antioxidant activity of purple-fleshed potatoes as affected by boiling, Journal of Food Composition and Analysis, 30(1), 6-12 (2013)

Burgos, G.; S. Auqui; W. Amoros; E. Salas; y M. Bonierbale, Ascorbic acid concentration of native Andean potato varieties as affected by enviroment, cooking and storage, Journal of Food Composition and Analysis, 22(6), 533-538 (2009)

Burgos, G.; E. Salas; W. Amoros; M, Auqui; L. Muñoa; M. Kimura; y M. Bonierbale, Total and individual carotenoid profiles in Solanum phureja of cultivated potatoes: I. Concentrations and relationships as determined by spectrophotometry and HPLC, Journal of Food Composition and Analysis, 22(6), 503-508 (2009)

Burlingame, B.; B. Mouillé ; y R. Charrondiére, Nutrients, bioactive non-nutrients and anti-nutrients in potatoes, Journal of Food Composition and Analysis, 22(6), 494-502 (2009)

Calliope, M.O.L.; y N.M. Samman, Biodiversity of Andean potatoes: Morphological, nutritional and functional characterization, http://dx.doi.org/10.1016/j.foodchem.2016.12.074, Food Chemistry, (2017) 
Chun, O.K.; Kim, D.O.; Smith, N.; Schroeder, D.; Han, J.T. y C.Y. Lee, Daily consumption of phenolics and total antioxidant capacity from fruit and vegetables in the American diet. J. Sci. Food Agric., 85, 1715-1724 (2005)

Dale, M.F.B.; Griffiths, D.W.; y D.T. Todd, Effects of genotype, environment, and postharvest storage on the total ascorbate content of potato (Solanum tuberosum) tubers. J. Agric. Food Chem., 51(1), 244-248 (2003)

Drewnowski, A.; y C.D. Rehm, Vegetable cost metrics show that potatoes and beans provide most nutrients per penny, https://doi.org/10.1371/journal.pone.0063277, PLoS ONE. (en línea), 8, e63277 (2013)

Faller, A.L.K.; y E. Fialho, The antioxidant capacity and polyphenol content of organic and conventional retail vegetables after domestic cooking, doi:10.1016/j.foodres.2008.10.009, Food Research International, 42(1), 210-215 (2009)

Faller, A.L.K. y E.F.N.U. Fialho, Polyphenol content and antioxidant capacity in organic and conventional plant foods. J. Food Compost. Anal., 23(6), 561-568 (2010)

Hejtmánková, K.; V. Pivec; E. Trnková; K. Hamouz; y J. Lachman, Quality of coloured varieties of potatoes, Czech Journal of Food Sciences, 27, 310-313 (2009)

Ježek, P.; Hlušek J.; Lošák T.; Jůzl M.; Elzner P.; Kráčmar S.; Buňka F. y A.M. Mårtensson, Effect of foliar application of selenium on the content of selected amino acids in potato tubers (Solanum tuberosum L.). Plant soil environ., 57(7), 315-320 (2011)

Karim, Zida.; Holmes, M.; y O. Caroline, Inhibitory effect of chlorogenic acid on digestion of potato starch, DOI: 10.1016/j.foodchem.2016.08.058, Food Chemistry, 217,498-504 (2017)

Lemos, M.A; M.M. Aliyu; y G. Hungerford, Influence of cooking on the levels of bioactive compounds in purple majesty potato observed via chemical and spectroscopic means, http://dx.doi.org/10.1016/j.foodchem.2014.10.064, Food Chemistry, 173, 462-467 (2015)

Liu Z., Chemical methods to evaluate antioxidant ability. Chem. Rev., 110(10), 5675-5691 (2010)

Loyola, N.; Oyarce, E.; y C. Acuña, Evaluación del contenido de almidón en papas (Solanum tuberosum Cv. desirée), producidas en forma orgánica y convencional, en la provincia de Curicó, región del Maule. Idesia (arica), 28(2), 41-52 (2010)

Miller, G. L. Modified DNS method for reducing sugars, Analytical Chemistry, 31(3), 426-428 (1959)

Molina, Y.; G. Rabe; M.L. Rodríguez; M.S. Cerón; y A.M. Garnica, Contenido de antioxidantes en papas criollas nativas (Solanum tuberosum Grupo Phureja) en procesos de precocción y congelación, Alimentos Hoy, 23(36), 31-41 (2015)

Navarre, D. A.; R.S. Payyavula.; R. Shakya.; N.R. Knowles.; y S.S. Pillai, Changes in potato phenyl propanoid metabolism during tuber development, http://dx.doi.org/10.1016/j.plaphy.2013.01.007, Plant Physiology Biochemistry, 65, 89-101 (2013)

Navarre, D. A.; R. Shakya; M. Holden; y S. Kumar, The effect of different cooking methods on phenolics and vitamin C in developmentally young potato tubers, DOI 10.1007/s12230-010-9141-8, American Journal of Potato Research, 87, 350359 (2010).

Ngobese, N.; T. Workneh; B. Alimi; y S. Tesfay, Nutrient composition and starch characteristics of eight European potato cultivars cultivated in South Africa, https://doi.org/10.1016/j.jfca.2016.11.002, Journal of Food Composition and Analysis, 55, 1-11 (2017)

Peña, C., Restrepo-Sánchez, L. P., Kushalappa, A., Rodríguez-Molano, L. E., Mosquera, T., y Narváez-Cuenca, C. E, Nutritional contents of advanced breeding clones of Solanum tuberosum Group Phureja, DOI: 10.1016/j.Iwt.2015.01.038, LWT - Food Science and Technology, 62, 76-82 (2015)

Re, R., N. Pellegrini; A. Proteggente; Y. Pannala; M. Yang; y C. Rice-Evans, Antioxidant activity applying an improved ABTS radical cation decolorization assay, Free Radical Biology \& Medicine, 26, 1231-1237 (1999)

Reddivari, L.; A.L. Hale; Jr. y J.C. Miller, Genotype, location, and year influence antioxidant activity, carotenoid content, phenolic content, and composition in specialty potatoes, Journal of Agricultural and Food Chemistry, 55(20), 8073-8079 (2007)

Rodríguez, D.; Nústez, C.E.; Cotes, J. M., y L.E. Rodríguez, Heredabilidad del contenido de proteína total en papa diploide Solanum tuberosum grupo Phureja. Bragantia, 70(4), 759-766 (2011)

Shakya, R. y D.A. Navarre, Rapid screening of ascorbic acid, glycoalkaloids, and phenolics in potato using highperformance liquid chromatography, Journal of Agricultural and Food Chemistry, 54, 5253-5260 (2006)

Vauzour, D.; Rodriguez-Mateos, A; Corona, G.; Oruna-Concha, M. J. y J. P. Spencer, Polyphenols and human health: prevention of disease and mechanisms of action. Nutrients, 2(11), 1106-1131 (2010)

Zaheer, K. y M.H. Akhtar, Potato production, usage, nutrition-a review. Crit. Rev. Food Sci. Nutr., 56(5), 711-721 (2016)

Zapata, K.; Cortes, F.B.; y B.A. Rojano, polifenoles y actividad antioxidante del fruto de Guayaba Agria (Psidium araca), Información tecnológica: 24(5), 103-112 (2013) 